\title{
Uma viagem ao inferno do outro: Medo de Sade, de Bernardo Carvalho.
}

\author{
Mayara Ribeiro Guimarães ${ }^{1}$
}

RESUMO: Tendo em vista as idéias de Georges Bataille sobre o erotismo; a escola da libertinagem do Marquês de Sade; e o conceito de transgressão de Foucault, analisaremos neste artigo o romance Medo de Sade, de Bernardo Carvalho, lendo no texto a relação erótico-sádica entre os personagens; a construção do real, por meio de uma linguagem elaborada num complexo jogo entre leitor e texto, numa estrutura narrativa dramática.

ABSTRACT: Starting from ideas on eroticism, by Georges Bataille; the school of licentiousness, by Marquis of Sade; and the concept of transgression, by Michel Foucault, this article aims to analyze the novel Medo de Sade, by Bernardo Carvalho, by considering the erotic-sadistic relationship among its characters; the development of reality, by means of an elaborated language, into a complex play among reader and text, into a dramatic narrative.

PALAVRAS-CHAVE: Bernardo Carvalho, Literatura contemporânea; narrativa dramática, erotismo.

KEYWORDS: Bernardo Carvalho, contemporary literature; dramatic narrative, eroticism.

Do erotismo é possivel dizer que ele é a aprovação da vida até na morte.

(Georges Bataille , O erotismo)

Publicada em 2000, a sexta obra de Bernardo Carvalho dá continuidade ao trabalho literário iniciado pelo autor em 1993 com o livro de contos Aberrações e mantém em vigência a elaboração da estrutura narrativa, tão marcante na obra de Carvalho. Tal construção narrativa toma a forma de seqüências e diálogos que se aproximam da estrutura de uma peça teatral, desde a utilização do discurso direto livre, até a criação de locações especiais para a trama, o corte seqüencial para a introdução de novas marcas temporais em atos

\footnotetext{
${ }^{1}$ Doutoranda em Literatura Brasileira. Universidade Federal do Rio de Janeiro (UFRJ). Pesquisa: Estudos da Narrativa Brasileira. E-mail: mayribeiro@uol.com.br
} 
dramáticos, e a própria encenação farsesca dos personagens. A composição de uma trama encenada pelos personagens em tempos, locais e situações diferentes a cada seqüência aponta para o tema central do romance: o jogo - erótico, mortal, teatral - que se instala na relação dos personagens e na relação narrador-leitor.

Assim sendo, interpretaremos o romance de Carvalho sob o prisma da relação erótico-sádica que se estabelece entre os personagens, vindo a interferir na construção do real por meio do trabalho com a linguagem estruturada em jogo textual complexo, que intervém na relação leitor-texto. Visa-se, ainda, avaliar como este jogo elaborado pela narrativa contemporânea se estende para o estatuo do narrador, problematizando a relação entre este e os personagens, a noção entre real e ficcional e o deslocamento temporal e espacial realizado pela narrativa. Nesse ponto, o diálogo entre a tradição e o novo se apresenta como releitura do passado histórico no presente ficcional do romance urbano do século XXI de forma a proporcionar ao leitor a reavaliação crítica do passado. Para tal, trabalharemos com as idéias de Georges Bataille sobre o erotismo, a escola da libertinagem do Marquês de Sade e o conceito de transgressão oferecido por Foucault.

$\mathrm{O}$ ato de transgredir constitui-se como gesto que toca o limiar entre vida e morte, elementos vitais à permanência da literatura. A experiência de vida se torna tão latente e desejada quanto a experiência de morte, ambas vividas no estertor da palavra literária, de modo que uma e outra se aprovem e se conjuguem mutuamente. O erotismo (a obscura força da luz de Eros), por sua vez, constitui-se como o entrelugar em que a vida se abre para a morte, o bem para o mal, o luminoso para o obscuro, o esconso e o visível, o oblíquo e o reto, em constante movimento de destruição da estrutura do ser fechado em nome de um estado de continuidade que garante a experiência de unidade do espírito humano.

Em seu livro O corpo impossível, Eliane Robert Moraes aponta que na passagem do século XVIII ao XIX ocorre uma mudança de paradigma da imagem ideal do homem para a construção de um imaginário do 
dilaceramento, cujo objetivo era lançar a forma humana aos limites da sua desfiguração. Evidentemente, tal projeto se estende até o século XX, com as manifestações surrealistas e a redução do princípio da identidade humana ao imperativo do desejo. Com isso, a imagem do homem vai se transformando, passando das duplicações de identidade até a sua finitude completa na figura da cabeça degolada de João Batista. Com a parábola do amor impossivel entre Salomé e João Batista, engendra-se a idéia de uma paixão que consome a si mesma, aproximando amor e morte em jogo mortal, onde a coreografia dos sete véus oferece pouco ao leitor e mantém a tensão entre luz e sombra (MORAES: 2002, 33). Mas a principal mensagem de Salomé consiste na noção de que somos todos assassinos daquilo que amamos. Não só assassinamos, mas decapitamos. E o horror da decapitação da cabeça, em cuja testa pousa o beijo da mulher, justapõe-se ao encanto da dança sensual criando uma história do olhar, já que o que atrai e faz-nos procurar o que se esconde por trás do sexo é o mesmo que nos repele o olhar da cabeça amputada. Como aponta Eliane Robert Moraes: "Talvez não seja apressado adiantar que essa aproximação entre a sexualidade difusa de Salomé e a cabeça decapitada de S. João Batista atenta para um tema que a modernidade estética não se cansará de representar: a perda da unidade do corpo. Estamos, portanto, no domínio da morte" (Moraes, 2002, p. 36). Poderíamos acrescentar: estamos no domínio do erotismo. Pois, como diria Bataille: o erotismo é a aprovação da vida até na morte. Estamos, portanto, no domínio de Bernardo Carvalho. Mas, anunciar a perda daquela unidade é promover também o apagamento da identidade, condição do sujeito que nasce com o romance moderno e se estende até o século XXI. A "nova literatura brasileira" problematizará o referente da narrativa a partir do questionamento do narrador como ponto de referência e coerência, uma vez que o olhar da literatura se volta para a alteridade, seja ela o indivíduo, o passado histórico-social ou a tradição literária. Visa-se a inserção do outro no contexto narrativo pela aceitação das diferenças e o reconhecimento de que a realidade social vivida pelo homem contemporâneo e suas 
experiências presentes da vida urbana são estruturadas por discursos múltiplos. Nota-se a preocupação em construir uma narrativa que privilegie menos as experiências do narrador e mais as atitudes e situações vividas pelos personagens. A informação narrada é elaborada como ênfase do olhar sobre os indivíduos, fatos e incidentes cotidianos e pelo distanciamento do narrador. É essa consciência distanciada que permite o "conhecimento" da vida e experiências alheias e abre a via para o trabalho de construção da linguagem. Apresenta-se, nesse ponto, uma das questões mais privilegiadas da narrativa pós-moderna: a da autenticidade. O ofício do ficcionista contemporâneo consiste em narrar as ações alheias, construindo o real a partir do exercício da linguagem, oscilando entre diferentes registros discursivos, como o da crônica, o da historiografia, o ficcional, o jornalístico, de forma que a fronteira entre vida e arte se obscureça e a autenticidade das ações romanescas se confunda.

Nesse momento, a coerência geradora de significados fica comprometida e a literatura se abre para as várias possibilidades de atribuição de sentido ao real e ao passado. Abre-se para o debate a partir da traição e reconciliação com a palavra do passado, para o diálogo entre a tradição e o novo, realizando a gênese de um novo mundo. Nesse novo cosmos importa pouco a veracidade dos fatos ou de quem é a verdade que se conta, mas a revisitação do passado, o questionamento dos valores estéticos e morais de uma tradição, sempre partindo de uma narrativa irônica e pouco inocente. O pós-modernismo entende que o desafio e o questionamento são valores positivos por se mostrarem como condição possível para a mudança. A via de comunicação possível entre narrador e personagem, consciência distanciada e experiência aproximada, realiza-se por meio do olhar crítico. A incomunicabilidade entre as duas instâncias literárias é tamanha que não há troca possível ou diálogo interpessoal, apenas a visão analítica e remota, na tentativa de dar conta de um momento de crise na contemporaneidade dramatizado na precariedade do presente e no distanciamento entre os indivíduos. É nesse momento que a noção 
de "presença do passado" (Hutcheon, 1991, p. 39), apontada pelos teóricos do pós-estruturalismo, apresenta-se como fator condicionante da acentuação do caráter de abertura aos múltiplos discursos. Com o distanciamento entre narrador e personagem, o olhar daquele se volta para as ações deste no que apresentam de diferença dentro da semelhança. A ação que envolve a ambos muitas vezes é a mesma, em tempos diferentes, porém a atitude adotada por cada uma das partes diante dos fatos muda. O narrador pós-moderno "não quer enxergar a si no ontem", e por isso se subtrai enquanto provedor da experiência em lugar da visão, sem desistir, no entanto, de querer "observar seu ontem no hoje" (Santiago, 1989, p. 48) do ser humano.

A literatura, portanto, lançará mão de estratégias discursivas como a paródia, a ironia, o pastiche, em diálogo com seu passado artístico e sociocultural, cumprindo a tarefa de reavaliá-lo e reelaborá-lo criticamente. Os artistas pós-modernos buscam consolidar pela semelhança e questionar pela diferença princípios como sentido e identidade. Não se trata de um aprisionamento no passado ou de sua negação, e tampouco da busca de algum sentido atemporal, mas de um desafio libertador promovido pelo confronto e pela reescritura, o que permite a reavaliação crítica e o diálogo do passado à luz do presente.

Diante dessas considerações, Medo de Sade apresenta-se no seguinte registro: dois atos, uma história - duplicação do mesmo. "Os números e o sentido" (CARVALHO, 2000:71), diz o narrador do ato dois. A começar pelo fato de que o real perde os limites. A começar pelo fato de que as duas histórias elaboradas por Carvalho e divididas em dois atos, como numa peça teatral, intercalam-se uma na outra. A primeira, supostamente passada em um castelo francês do século XVIII, tem como personagem principal um barão libertino que, após ver-se envolvido em um assassinato, é enviado ao hospício de Charenton, onde o próprio Marquês de Sade foi internado. A segunda, no Rio de Janeiro, envolve um casal de franceses que elabora um jogo chamado "Medo de Sade" como forma de preenchimento de sua relação falida. Seria o ato um apenas a história de um dos livros do barão de LaChafoi, 
personagem fictício criado por Carvalho aos moldes de Sade? "Num de seus livros, um romance moral em diálogos, o barão contava como tinha se vingado da mulher que o traía: deflorou a filha bastarda que ela tivera com o primo dele" (idem). Ou seria o ato um, ao contrário, um ato de delírio de alguém que perdeu o contato com os domínios da sanidade? Como aponta a voz do narrador sobre a súbita loucura do homem (e não por acaso, todos os personagens são anônimos, com exceção do barão, Martine e o conde de Suz, e o personagem ausente que se encontra no título da obra, porém jamais presente ao longo do romance: Sade): “Chegou aqui dizendo que era o barão não sei do que à procura do Marquês de Sade. [...] Acha que está num hospício francês no início do século XIX e que só o marquês pode salvá-lo. [...] Tem medo. Tem alucinações. Vê coisas. [...] Ouve vozes. Fala com elas" (CARVALHO, 2000:106).

Revela-se, logo de início, a arquitetura complexa da estrutura narrativa criada por Carvalho em trabalho labiríntico com a inteligência do leitor, o qual assume papel fundamental na construção do significado do enigma proposto pelo autor. O discurso literário rompe com o compromisso das representações que a linguagem traz consigo, usurpando o real e criando o seu próprio mundo ficcional, que envolve os personagens de ambos os atos. Nesse movimento, estabelece-se uma relação de jogo sádico entre os personagens de Carvalho do segundo ato - o homem e a mulher - a partir de um pacto de vida e morte. "Resolveram que o melhor era estabelecer uma relação baseada na traição e no horror. O horror no lugar do amor" (idem, p. 68). O jogo erótico esconde por trás a perda da unidade identitária, representativa do homem moderno, que garante a sanidade. O pacto é realizado precisamente após a descoberta de um primeiro ato de traição realizado pela mulher: a automutilação. "Seis meses depois de casados descobriram que ela não podia ter filhos. Perceberam que o amor não resiste ao tempo, o amor acaba, e fizeram um pacto explícito [...]" (idem, p. 68). O pacto idealizado por Carvalho propõe a experiência de viver um casamento "baseado num jogo de horrores" no qual "cada um dos 
cônjuges prega uma peça no outro, alternada e sucessivamente”, com o objetivo de viver sob o jugo do medo porque "quem tiver medo, perde" (ibidem).

O pacto vivido pelos personagens reflete-se como tentativa de manter a relação amorosa próxima a algum centro pulsante de vida, ainda que pela afirmação da morte, já que a possibilidade de existência é sempre estrangulada pela subjetividade fragmentada. A manifestação desta fragmentação atinge inclusive a relação do sujeito com o próprio corpo: o único órgão produtor de vida, o útero, é extirpado pela mulher. Ao perceber que o prazer causado pelo horror estaria sempre condenado, já que "a vida é um incentivo ao crime" (p. 45), a mulher decide que, para dar continuidade a este mesmo prazer, segundo os ensinamentos do barão, é necessário estar sempre beirando a morte. O leitor descobrirá, aos poucos, que o maior dos libertinos desta farsa teatral não será representado pela figura do homem, mas pela mulher, personagem que evidencia os motivos condicionadores de sua automutilação como decorrentes da infância subjugada ao sacrifício e à perda. O jogo mortal, orquestrado e proposto pela mulher, tem início desde o seu primeiro ato consciente de mutilação, prefiguração do grand finale "à maneira americana", do qual sai vitoriosa e que revela a encenação desse teatro de horrores que é a vida privada do homem. O mundo é uma farsa e o real é a construção de significados e verdades.

$\mathrm{O}$ ato de auto-imolação esconde o perigo de se fraquejar ante o amor ou qualquer outro sentimento vital. $O$ autor desvela a complexidade da alma humana e revela a construção de representações ou simulacros que apenas forjam um real. Para a Voz, no primeiro ato, é justamente a escravidão aos sentimentos e às convenções que estimula a construção de simulacros e mentiras. A denúncia da irracionalidade do real e de suas convenções é feita, primeiramente, pela Voz, e depois repetida no segundo ato pela mulher, duplos um do outro. Assim o autor desmascara as verdades impostas e afirma a crença de que a vida é uma ficção, um grande teatro construído pelos diferentes discursos através da linguagem, e que a literatura é talvez a 
única possibilidade de libertação das amarras das representações. Assim como a Voz e a mulher estabelecem uma relação de co-valência, o barão e o homem mostram-se um como o duplo do outro. A verdade é, portanto, oferecida pela Voz, no ato um, e pela mulher no ato 2: se "tudo é convenção", (CARVALHO, 2000:50) então é necessário "duvidar de todas as certezas", "até (d)as mais básicas" (idem, p. 49). E nesse momento desconfia-se que a voz já não é mais dos personagens, mas da própria Literatura. E, ainda, submeter-se às regras e jogos elaborados pelo barão, como propõe a Voz, é submeter-se à viagem maravilhosa pelos mundos criados pela literatura. O pacto já não é mais puramente ficcional, mas passa ao domínio do real, tornando-se pacto entre leitor e texto literário, que consiste em destruir, senão todas, pelo menos algumas de nossas certezas mais básicas, a partir da exigência da submissão total e completa ao teatro das ficções, atirando-nos a um mundo em que as fronteiras entre vida e arte são desfeitas.

Assim, se a mulher prepara toda a farsa, inclusive o movimento final no momento de sua morte, revelando que ela é a grande libertina e algoz, a nós também, leitores, é revelada a verdade da qual todos somos vítimas: a vida é um jogo que diante de nós se desenrola, como o texto, e seu algoz é o autor, que nos prega mais essa cilada.

À luz do teatro de Sade, a farsa inventada por Carvalho faz referência direta ao Marquês no ato um a partir da criação de uma peça que se assemelha bastante aos moldes do teatro sadiano e, no ato dois, a partir da reencenação da história nos moldes contemporâneos. Se, no primeiro ato, a ambientação é de uma alcova em alguma masmorra na França do século XVIII, o segundo ato passa-se em cenários da atualidade, mas a mesma encenação teatral amorosa se desenrola. A imagem da alcova (parte sala de sanatório, parte cela de prisão), bem como o tratamento dado ao ato criminoso, trazem à tona a discussão da fronteira entre crime e loucura.

Como aponta Foucault na História da Loucura, os libertinos no século XVIII eram internados junto aos loucos, apesar de não serem rotulados como tais e tampouco como criminosos. A partir da Revolução 
Francesa, o crime perde o seu sentido absoluto e passa a ser considerado pelos seus aspectos público e privado. No aspecto privado, aponta Moraes (1994:128), o crime torna-se delírio e, no aspecto público, manifesta-se como desumano e insensato. Em outras palavras, difere-se entre o crime e a loucura. O teatro aproxima-se do tema por ser entendido por alguns a partir das encenações teatrais de Sade, em seu conteúdo terapêutico. Ao investir o corpo como "lugar de uma energia natural a ser resgatada através da crueldade" (MORAES, 1994:130), o teatro sadiano parece oferecê-lo ao indivíduo como espaço para se realizar e se concretizar enquanto $e u$. Se assim é, a peça que se desenrola terá sempre como imperativo o assassinato sobre todos os sentidos. É essa a verdade que a Voz, na obra de Bernardo Carvalho, parece nos oferecer: o prazer máximo e último do libertino é o assassinato. "Você não sabe qual é o maior ensinamento? Que o prazer culmina no assassinato e na morte? Não pode haver nada superior que matar por prazer" (CARVALHO, 2000:46). No jogo erótico da crueldade, da tortura e do assassinato, o que se visa é a fruição do mal (cf. MORAES, 1994:136). Podemos concluir que o ato um constitui-se, portanto, como prefiguração do pacto mortal que se estabelecerá no segundo ato, nos moldes da peça pregada por Martine, pelo Conde de Suz e pela baronesa no pobre barão de LaChafoi.

O teatro de Sade é também o teatro do "ver e do ferir", como afirma Moraes. Se entre súditos e senhores estabelece-se uma relação em que os primeiros são obrigados a participar da cena sexual e os últimos, além de participarem e assistirem, podem ainda intervir na atividade sexual e visual, pode-se dizer que a mesma relação se estabelece entre espectador e diretor. E se o libertino é aquele que não só atua, mas também dirige o espetáculo, espera-se que o leitorespectador atue não só como observador, mas como diretor também, intervindo com suas próprias imagens (cf. MORAES, 1994:134). Ora, acreditamos que a estrutura criada por Carvalho em Medo de Sade tematiza não só o jogo cruel do teatro sadiano, mas também a sua estrutura. Assistimos ao espetáculo de horror e morte entre dois 
libertinos, cujos papéis de algoz e vítima alternam-se a todo o momento, para ao fim fazer da mulher a verdadeira senhora e do homem nada além de seu súdito. Assim também se estrutura o primeiro ato, no qual o barão atua no papel de vítima sacrificada, ainda que se dissesse o maior seguidor dos ensinamentos sadianos, enquanto os outros personagens aparecem como os libertinos que dele se aproveitam, em espetáculo de cruel enlouquecimento. O leitor, por sua vez, delicia-se com o joguete labiríntico dirigido pelo narrador, participando através da construção do sentido e, ao mesmo tempo, sendo vítima da piada do autor, já que a literatura é também ato lúdico.

Uma vez mais, a partir das citações nietzschianas, Moraes aproxima a arte da libertinagem do teatro ao lembrar-se do axioma "ver sofrer faz bem, fazer-sofrer mais bem ainda” (idem, p. 137), por meio do qual o fazer-sofrer atua como um chamariz à vida. Entre nossos personagens, o fazer-o-outro-sofrer permite que se viva no limiar das paixões humanas, reinaugurando o pacto de vida e morte a cada novo ardil e garantindo que a atração excitante do perigo se aproxime da presença pulsante da vida.

Segundo Bataille, o erotismo implica sempre violência e violação pela proximidade dos domínios da morte e do ato de matar. Por isso, "toda realização erótica tem por princípio uma destruição da estrutura do ser fechado" (BATAILLE, 2004:29) e uma das vias dessa dissolução é o ato sacrificial. Assim, o erotismo estabelece um paralelo entre o ato de amor e o ato de sacrifício e exige uma vítima. Em Medo de Sade, nota-se que a única maneira dos personagens manterem o casamento é elaborar o pacto no qual o amor é substituído pelo horror, de modo que a continuidade do horror motive o exercício da vida. Se o amor não pode garantir sentido à vida, entra em cena a proximidade da morte: é preferível matar o ser amado a não tê-lo porque "o movimento do amor, levado ao extremo, é um movimento de morte" (BATAILLE, 2004:64). Assim é que o desejo pela mulher só se revigora quando movido pela proximidade da morte no ato sexual e sacrificial anterior à imolação da vítima. "Estava tomado pela excitação mórbida de pensar que aquele 
corpo que se entregava a ele estaria morto em menos de dois dias" (CARVALHO, 2000, p. 100). O pacto consiste, portanto, em manter o casamento "sob o princípio da traição" (Carvalho, 2000, p. 68), assim estariam fugindo às convenções impostas e vivendo somente do prazer de pregar peças e do instinto necessário à sobrevivência, como recomenda a Voz à página 50 .

As traições consistiam em pregar peças um ao outro, "uma mais horrivel que a outra, e assim pretendiam se manter unidos até a morte" (idem, p. 69). Quanto mais estendessem o pacto mais prazer sentiriam por estarem sempre à beira do precipício, vivendo a consciência da morte. Entretanto, ao planejar a morte da mulher, o marido rompe com as regras do jogo e troca consciência por iminência. "Porque até a traição tem suas regras, e ele trapaceou. [...] Quis adiantar a morte, matar a mulher antes que ela o matasse. Teve medo. E nesse jogo quem tem medo perde" (ibidem). Se, no ato erótico vivido dois dias antes da morte da mulher, o personagem estivesse de fato "desperto para gozar o maior de todos os gozos" (idem, p. 22), perceberia que a leitura do trecho do livro do barão, realizada pela mulher durante o ato de amor, revelava exatamente o paradoxo daquele homicídio. A leitura do texto configura-se como o epitáfio da própria mulher, metáfora do que havia sido sua vida e seus atos: "Eu te exorto, minha querida, a fazer de mim um instrumento da tua vingança e do horror" (idem, p. 100). Mas o homem, "mal ouvia o que ela lia em voz alta [...] enquanto ele gozava como um surdo" (idem, p. 100-101), embora a lição tenha sido ironicamente memorizada e relembrada ininterruptamente pelo marido depois da morte da mulher.

Claramente, trata-se de um jogo sádico em que a mulher é a grande libertina e o marido o seu súdito e, de acordo com a escola da libertinagem do Marquês de Sade, somente os senhores podem interferir no ato sacrificial, não os súditos. A mulher é a grande libertina uma vez que, desde a primeira automutilação, já se preparava para o jogo de morte instituído por ela, além de estabelecer as regras "segundo a filosofia do barão" (idem, p. 71). E como o barão havia se tornado seu 
mestre e com ele aprendera as lições aplicadas na vida, seus ensinamentos tornam-se regras imperativas neste jogo macabro condicionador das relações afetivas: "[...] ela lhe propôs aquele jogo. Inspirada na filosofia do barão e na própria infância” (idem, p. 73). A lição de que "só a traição liberta" (idem, p. 71) torna-se a única possibilidade de libertação do inferno emocional em que se transformaram as relações amorosas, das suscetibilidades e fraquezas construídas pelas "vontades contraditórias" dos sujeitos e principalmente das mentiras inventadas para "justificar o que não se pode explicar”, como Deus e o amor (idem, p. 81). A prática da traição consistia em libertar-se das convenções impostas a partir da inversão dos valores e virtudes, na qual "o mal é o bem e a traição, a honra. Um mundo de desvirtudes como única forma de escapar à hipocrisia da religião e aos limites das convenções humanas em nome da verdade dos instintos” (idem, p. 72). Matar seria impedir que a continuidade dessa lição.

Entretanto, ao aceitar a farsa, a mulher cumpre o papel da vítima, mesmo sabendo que, ao mudar as regras, o marido não se dera conta de seu fim, e cumpre o rito sacrificial a ela imposto. Segundo Bataille, "o sacrifício [...] é uma representação teatral, um drama reduzido ao episódio final, no qual a vítima animal ou humana representa sozinha, mas representa até a morte” (BATAILLE, 2004:137). Ao assumir seu papel de mártir, a mulher entra no jogo uma vez mais e o pacto do silêncio se estabelece até o fim. Sabe que após o medo se instalar, não havia mais volta. Ele também o sabe, mas por orgulho escudo do medo - decide compactuar com o silêncio:

Sabia que ela podia estar jogando verde ou fazendo uma provocação equivocada sobre a aparente e inesperada crise de ciúmes da tarde. Sabia que ela podia estar falando de outra pessoa, e não do cliente. Sabia que ela podia não estar sabendo de nada. Mas não podia abrir o flanco. [...] Ele só não sabia é que com a morte dela quem morria era ele. (CARVALHO, 2000:79). 
Assim cumpria o marido o mesmo destino que o barão no primeiro ato: o de vítima ignorante. "Cada um vê o que quer - ou o que pode" (idem, p. 63), repete a Voz insistentemente, tal qual mote que ecoa ao longo de todo o romance. A repetição, estratégia constantemente adotada pelo autor como meio de transformar a verdade a cada nova afirmação ocorre em momentos específicos de modo a criar efeito irônico, como no exemplo dado. Somente no momento final do sacrifício o homem compreende que, a todo o tempo, era a mulher quem estava no comando e não só havia dito a frase que lhe selou o destino, mas fez questão de ser a última a pregar a peça e a pagar o ato de traição mortal que ele lhe havia feito. O horror é a única coisa que não morre.

Se há um perdedor do "Medo de Sade", este é o homem, não porque matou a mulher, uma vez que "o prazer culmina na morte", mas porque o ensinamento se realiza pela escola do medo. O homem perde o jogo porque a motivação do assassinato não foi o prazer, senão o medo, porque o grande mobilizador deixou de ser o gozo para se transformar em medo e pavor e, com isso, apressar o fim do jogo. Fraquejando, o marido oferece à mulher, como dádiva, a consciência da iminência da morte e elimina um dado fundamental em qualquer jogo: o acaso. "O acaso sempre tinha sido um elemento fundamental. Não estava certo eliminar o acaso" (idem, p. 74). Ao planejar cada detalhe da morte da mulher, de modo que não houvesse dúvida de que escaparia, o homem havia eliminado o acaso. Quando decide matar, o homem abre a porta para a loucura.

Se o episódio de Salomé e a cabeça decapitada de João Batista apontam para a perda da unidade do corpo nas narrativas do século XVIII e XIX, nota-se que o século XX assiste a um processo de fragmentação e decomposição do sujeito como parte da definição do espírito moderno. Após as guerras que tomam conta da primeira metade do século XX, observa-se que as formas estéticas de pensar e sentir passam a se submeter a uma dinâmica do efêmero levando à criação de personagens desintegradas de si e a estruturas fraturadas. $\mathrm{O}$ 
mundo passa a revelar-se em pedaços, como forma de representação da desintegração da ordem existente; e o mundo estético e literário assiste à fragmentação da consciência e do corpo humano. As idéias de decomposição e desintegração associam-se às noções de alteração e morte de um corpo humano que começa a ser destruído, junto à sua identidade. É o século do “corpo em crise” (MORAES, 2002:63). O corpo e os objetos, liberados de suas definições funcionais, submetem-se ao imaginário e ao desejo. Com a ausência do objeto e do corpo humano como um todo, já que a impossibilidade de ser visto ou tocado tornava-o um fantasma, a potência imaginária do desejo e da imaginação ganha destaque. Ambos passam a operar no domínio do sonho e do delírio, das imagens mentais e sensações internas que fazem surgir as relações sexuais (MORAES, 2002:69). E a fúria do desejo e da violência, tão característica da obra sadiana, começa a interessar a literatura novamente em suas imagens de prazer e dor. Tais imagens revelam um corpo transfigurado em estado de terror e de êxtase, sensações opostas que começam a mudar o paradigma de beleza, ao passo que duvidam da representação das formas e deslocam os sistemas de referência. Em outras palavras, começa-se a desconstruir as convenções do mundo da arte e as verdades construídas pelo real.

Observaremos que a referência à obra do Marquês de Sade, em um século que vê deslocada a condição do homem, colocado por sua vez em um universo de metamorfose, destaca o ponto em que se enxerga sua a destruição como "princípio de transmutação da matéria" (MORAES, 2002:85). Esse princípio tem por trás não o desejo de simples destruição da matéria, mas da conquista de novas estruturas.

A tentativa de estabelecer novas regras como maneira de encontrar novas formas de existência e de recuperação do casamento, na obra de Bernardo Carvalho, já que os personagens perdem o sentido identitário de suas vidas, tem êxito até o ponto em que se realiza o ato de morte. Não é possível recuperar a unidade do corpo ou da identidade, uma vez que se chega tão próximo da morte. O choro purificador da mulher no momento em que reconhece a chegada da 
morte garante um pouco mais de humanidade a essa libertina que assume o seu destino de jogadora e atriz na grande farsa criada no teatro da vida. Porque, como afirma o narrador no início do segundo ato, nesse jogo amoroso e mortal, não importa quem matou quem, vida e morte caminham sempre juntas, assim como os vícios e as virtudes. $O$ que importa é "o paradoxo do homicídio" (CARVALHO, 2000:67), isto é, a ironia do jogo, que permite tantas formas variadas de se jogar, onde nada é o que parece ser, tudo é jogo de imaginação, e o real é uma ficção que construímos para preencher, no inferno nosso de cada dia, o sentido de nossa vida vã e falha.

\section{Referências Bibliográficas}

BATAILlE, Georges. O erotismo. São Paulo: Arx, 2004.

CARVALHO, Bernardo. Medo de Sade. São Paulo: Cia. das Letras, 2000.

FOUCAULT, Michel. Ditos e Escritos - Estética: Literatura e pintura, música e cinema. Vol. III. São Paulo: Ed. Forense Universitária, 2000.

HUTCHEON, Linda. Poética do pós-modernismo. Rio de Janeiro: Imago, 1991.

MORAES, Eliane Robert. O corpo impossível. São Paulo: Iluminuras, 2002. Sade. A felicidade libertina. Rio de Janeiro: Imago, 1994. 